\title{
Diagnosis of functional illness presenting with gait disorder
}

\author{
A P J THOMSON AND J A SILLS \\ Royal Liverpool Children's Hospital (Alder Hey), Liverpool
}

SUMMARY Nine children presented with disturbances of gait that were not caused by organic disease. They all fulfilled at least four out of eight diagnostic criteria. Diagnosis in all had been delayed while organic causes were excluded. Unnecessary and sometimes potentially harmful procedures were performed or proposed for each child. Identification of such children earlier may avoid morbidity and facilitate management.

Goodyer and Taylor summarised the diagnostic criteria that may aid the clinician in identifying functional disease. ${ }^{1}$ These include a history of important events in the child's life, covert family problems, similar symptoms in the past, important information concealed even on direct questioning, a person with similar symptoms in the child's family or peer group, and a discrepancy both between the symptoms and the signs and between the deficits elicited by functional testing and those found on formal clinical examination. Lastly, despite the apparent seriousness of the presentation, the signs elicited suggest neither an anatomical site nor a physiological reason for the lesion. The features tend to correspond to the patient's idea of physical illness, and the symptoms may serve an unconscious need.

We report nine cases of functional disease in which gait disturbance was the presenting feature. Eight criteria that aided the diagnosis of hysteria are examined for each case, and their relevance to this group of patients discussed. All children were seen in the rheumatology clinic, except for one who was referred to the neurology clinic.

\section{Case reports}

CASE 1

A girl was referred with a three week history of being unable to walk associated with pains in the right knee and ankle that were severe enough to prevent her attending school. She had had intermittent fever for six months that was resistant to aspirin; general malaise and sore throat for four weeks; and aches in her neck, left arm, and left chest for three weeks.
She entered the room hopping on her left foot, and was extremely apprehensive and difficult to examine. There were, however, no signs of inflammation in the right leg, or any other abnormal findings. She was admitted to hospital for assessment during which time she was not feverish, and her movements were less restricted when she thought she was unobserved. C-reactive protein concentration, erythrocyte sedimentation rate, $x$ ray pictures of the ankles, knees, and hips, and bone scan of the ankles were all normal.

A functional illness was suspected, and further investigations were postponed. Assessment by the physiotherapist confirmed the discrepancy between her claimed abilities and actual function. Enquiry elicited that she had recently been bullied at school, and that her symptoms started after this. She was discharged home having physiotherapy to aid mobilisation, and had recovered completely after two weeks. She subsequently changed schools.

CASE 2

A boy was referred to the orthopaedic clinic with a throbbing pain in his right hip after a fall on wet leaves when playing rugby football. Due to his father's change of job the family had recently moved to the area from a distant part of England where he had twice been admitted with an 'irritable hip' that had settled after traction.

There were no abnormal physical signs, and his erythrocyte sedimentation rate and $x$ ray picture of the hip were normal, so rest was advised. During the next weeks he deteriorated despite traction, physiotherapy, rest, gentle mobilisation on crutches, and hydrotherapy. A bone scan suggested Perthes' disease, but a repeat bone scan and radiographs 
appeared normal. Operation was considered, but he was referred for the rheumatologist's opinion first.

He had by now had symptoms for nine months, and had needed crutches for 12 weeks. He was hopping for four to five hours a day to remain mobile, and sometimes used a wheelchair. There was, however, no evidence of muscle wasting, and rotation of the hip was normal. He had a full range of knee movements. He could kiss both knees thus showing a degree of mobility that he denied when tested formally. Further enquiries showed that he had been under considerable stress before the illness. After the recent move he had disliked his new school and preferred the tuition at home that had been arranged for him while his symptoms persisted.

He was referred to a child psychiatrist who diagnosed a functional illness that had started after he had had a genuine irritable hip. He was mobilised with physiotherapy, and improved in the first four weeks. The family then stopped attending psychotherapy sessions. Three months later he suffered a relapse. The family were contemplating a move back to the area of England where he had been happiest, and they failed to keep further appointments.

\section{CASE 3}

A girl was referred by her general practitioner. She had had a sore throat that had been followed by weakness of her legs that had confined her to a wheelchair for three weeks. She had recently started at secondary school where she was said to be progressing well.

She was a prepubertal girl who was anxious when examined, but seemed otherwise remarkably untroubled by her illness. Her lower limbs were not wasted but she would not move them. She could stand hesitantly, but was unsteady if she tried to walk. Two weeks later, however, she seemed to have developed clonus in her right ankle and bilateral increased knee jerks though the plantar reflexes were downgoing. She was admitted to hospital for investigation to exclude a spinal lesion. Spinal $x$ ray pictures, examination of cerebrospinal fluid, myelogram, erythrocyte sedimentation rate, and virological titres were all normal. A provisional diagnosis of transverse myelitis was made, and she was treated with physiotherapy.

After two weeks her walking had deteriorated further, so she was admitted to hospital for reassessment. The nursing staff noticed that her symptoms fluctuated in severity, being worst while her overprotective mother or a member of the medical staff was nearby. Assessment by the physiotherapist confirmed that there were no abnormal signs, and muscle function during hydrotherapy was better than on formal testing. A psychiatrist discovered that the girl had twice had similar symptoms following minor illnesses several years before, and that she had recently been teased at school; both these facts had been concealed until then. He diagnosed a functional illness and told the girl and her mother that the symptoms would resolve rapidly. She began walking the next day, and two weeks later she returned to school.

\section{CASE 4}

A 14 year old girl gave a history of 12 months of intermittent pain on the medial aspect of the right foot that sometimes woke her at night. She had missed at least four weeks of school, the family's annual holiday in Spain had been cancelled, and she had been confined to the house during the summer holidays. Three years previously she had complained of pains in both knees and the surrounding muscles but despite investigations no diagnosis had been made. The family had not attended follow up appointments.

Examination showed mild tenderness over the extensor digitorum brevis but no other signs, and $x$ ray pictures of the knee were normal. Remedial foot and ankle exercises produced no improvement, and two months later she was unable to bear weight on the right foot and needed crutches. There was, however, no evidence of arthritis, and she had a full range of passive movements at the ankle. Her degree of disability did not seem commensurate with the signs, so she was admitted to hospital for assessment.

Serum C-reactive protein concentration and erythrocyte sedimentation rate were normal, and a technetium 99 bone scan showed minimal asymmetry of the uptake of isotope in both ankles. Observation on the ward, meanwhile, confirmed that she was less disabled than her account had suggested. She was able to move on her bed without pain or stiffness.

A functional illness was suspected, further investigations were postponed, and a psychiatrist confirmed the diagnosis. She made a good recovery after seven weeks in a psychiatric ward. The precipitating and perpetuating factors never became clear, but academic pressure, bullying at school, and sibling rivalry for her father were all possibilities.

CASE 5

A girl was referred from the orthopaedic department for assessment with a 12 month history of pain in the left heel that had been precipitated by a fall during a crucial game of rounders and exacerbated by subsequent falls at school and in the local 
shopping area. She had been unsuccessfully treated with a below knee plaster and walking heel on two occasions six months apart, and physiotherapy was also unsuccessful. Local injection of hydrocortisone had been considered, but examination and investigation failed to confirm inflammation.

Her illness had forced her to give up dancing, which was her main recreation, and she was unable to take part in games at school. She had, however, managed to attend lessons on crutches for the previous six weeks. She had epilepsy that was controlled with carbamazepine. Her mother had been off work for several months three years previously with a slipped disc.

On examination there was slight puffiness round both achilles tendons but she had a good range of active ankle movements with no crepitus. She had full and painless passive movements of all other joints. There appeared to be a gross discrepancy between symptoms and signs, and the possibility that she had a functional illness was considered. The mother agreed with this assessment, volunteering the information that the symptoms seemed to be used to avoid stress.

After discussion with the parents, rehabilitation with intensive physiotherapy was started. She made a good recovery in five weeks, was encouraged to start dancing again, and to take part in all sports. She was well on review four months later, though she occasionally still missed sport at school.

\section{CASE 6}

A girl was referred from the orthopaedic department with a four month history of pain and stiffness in the left knee, which she could not extend. She needed crutches. Physiotherapy had apparently exacerbated the symptoms. Arthroscopy of the knee had been normal, after which her symptoms had progressed to the extent that she was unable to play games or join in with other children at school playtime.

She had had pains in the left elbow and knee in the previous year that were not diagnosed, and which resolved spontaneously. She was an only child whose parents had divorced six years previously. She saw her father every Sunday. Her mother had suffered from chronic osteomyelitis of the tibia since the age of 9 and had recently been referred to the local pain clinic.

She had full active movements of all joints except the left knee, which she was reluctant to move. Passive flexion of the left knee, however, was possible up to $90^{\circ}$ without pain despite considerable quadriceps spasm. In contrast to the history, passive extension of the knee showed a full range of painless movement. Because of the discrepant symptoms and signs, a functional illness was suspected. The physiotherapist said that the symptoms were inconsistent and fluctuant, and a psychiatrist confirmed the diagnosis.

The child's symptoms were thought to be an emulation of the mother's disability due to chronic osteomyelitis, and the friction between the divorced parents seemed to be a major factor. Within two weeks, although she appeared no better to her mother, she abandoned the crutches at school and returned to full activity. Her symptoms had resolved six months later.

CASE 7

A girl was referred by her general practitioner with a five month history of pains in the arms, stiff neck, and numbness of the fingers, followed by pains in the right knee. She had not been taking part in sports for the previous month.

She had previously been seen in the orthopaedic outpatient clinic and a collar and a splint were prescribed, with little benefit. Haematological investigations were normal. Her mother had cervical and lumbar spondylosis, and her father had recently had a subarachnoid haemorrhage.

The discrepancy between her symptoms and lack of signs suggested a psychological basis for her symptoms. Assessment by the physiotherapist confirmed this, and a programme of rehabilitation was started. Two months later she was back to full activity with only occasional pains in her knee. She mentioned that her father too was better.

\section{CASE 8}

A boy was referred for a second opinion by his general practitioner. After a fall he had complained of pain in the left hip for five months, and had been off school for three months. The previous year he had been admitted to hospital on four occasions with an irritable left hip, and had had an exploratory arthrotomy on the last occasion.

He had been born by caesarean section, and had been separated from his mother for some weeks after birth because she had been on traction for pains in her left leg. He was an only child in his first year at secondary school.

He was a tearful, obese boy who limped dramatically when asked to go to the examination couch, but apart from some antagonistic muscle action in his left hip there was no evidence of inflammation or restriction of active movement. After admission to hospital he limped only intermittently, but particularly when under observation. Haematological investigations were normal, as were thyroid function tests, serum immunoglobulin concentrations, Tine test, and culture of the urine. An ultrasound scan 
showed a possible small effusion in the left hip joint. A bone scạn was normal.

Assessment by the physiotherapist confirmed the discrepancy between formal signs and functional testing, and a programme of rehabilitation was started. Psychiatric consultation elicited the fact that his own anxiety about his health was reinforced by overprotective parents. His symptoms had not improved seven months later. The family defaulted from follow up, but attended the orthopaedic department again where the symptoms were treated as organic; synovial biopsy was repeated and the specimen was normal.

CASE 9

A 9 year old girl was referred by her general practitioner with a three month history of pain in the right knee followed by pains in both lower legs and difficulty walking after an injury to the right knee. Her mother was divorced but had a regular boy friend. Considerable social problems were suspected.

She was obese, hobbled and appeared to have painful feet. She had, however, good active and passive movements of all joints. There was a little puffiness around the right ankle but no consistent local tenderness.

She was admitted to hospital for investigation. Haematological investigations were normal, as were erythrocyte sedimentation rate, C-reactive protein concentration, latex test for rheumatoid arthritis, immunoglobulin concentrations, thyroid function tests and culture of the urine. Antinuclear factor activity was absent. Mild osteoporosis of the ankles

Table 1 Features of the nine patients with functional gait disorders

\begin{tabular}{|c|c|c|c|c|c|c|c|c|c|}
\hline & 1 & 2 & 3 & 4 & $\begin{array}{l}\text { Case No } \\
5\end{array}$ & 6 & 7 & 8 & 9 \\
\hline $\begin{array}{l}\text { Sex } \\
\text { Age at presentation }\end{array}$ & $\mathrm{F}$ & $\mathbf{M}$ & $\mathbf{F}$ & F & $\mathbf{F}$ & $\mathbf{F}$ & $\mathbf{F}$ & $\mathbf{M}$ & $\mathbf{F}$ \\
\hline $\begin{array}{l}\text { (years, months) } \\
\text { Length of history }\end{array}$ & 11,0 & 11,4 & 12,5 & 14,10 & 12,10 & 9,9 & 10,8 & 12,11 & 9,7 \\
\hline $\begin{array}{l}\text { (months) } \\
\text { Duration of gait disorder }\end{array}$ & 6 & 9 & 1 & 14 & 12 & 4 & 5 & 5 & 3 \\
\hline $\begin{array}{l}\text { at presentation (weeks) } \\
\text { Time from presentation }\end{array}$ & 3 & 12 & 3 & 4 & 6 & 16 & 4 & 14 & 12 \\
\hline $\begin{array}{l}\text { to diagnosis (days) } \\
\text { Time from diagnosis }\end{array}$ & 8 & 1 & 56 & 42 & 1 & 1 & 1 & 1 & 22 \\
\hline $\begin{array}{l}\text { to recovery (weeks) } \\
\text { Total time unwell }\end{array}$ & 2 & 4 & 2 & 8 & 5 & 14 & 4 & 32 & 21 \\
\hline $\begin{array}{l}\text { (months) } \\
\text { Length of follow up from }\end{array}$ & $61 / 2$ & 10 & $11 / 2$ & $171 / 2$ & 13 & $71 / 2$ & 6 & 13 & 9 \\
\hline $\begin{array}{l}\text { presentation (months) } \\
\text { Outcome }\end{array}$ & $\begin{array}{l}3 \\
\text { Good }\end{array}$ & $\begin{array}{l}3 \\
\text { Relapse; } \\
\text { did not } \\
\text { attend }\end{array}$ & $\begin{array}{c}4 \\
\text { Good }\end{array}$ & $\begin{array}{l}3 \\
\text { Good }\end{array}$ & $\begin{array}{l}4 \\
\text { Good }\end{array}$ & $\begin{array}{l}6 \\
\text { Good at } \\
\text { school; } \\
\text { poor at } \\
\text { home }\end{array}$ & $\begin{array}{l}13 \\
\text { Good; } \\
\text { knee } \\
\text { pains }\end{array}$ & $\begin{array}{l}28 \\
\text { Did not } \\
\text { attend; } \\
\text { attends } \\
\text { ortho- } \\
\text { paedic } \\
\text { clinic }\end{array}$ & $\begin{array}{l}5 \\
\text { Did not } \\
\text { attend }\end{array}$ \\
\hline
\end{tabular}

Table 2 Features aiding diagnosis in nine patients with functional gait disorders

\begin{tabular}{|c|c|c|c|c|c|c|c|c|c|c|}
\hline \multirow[t]{2}{*}{ 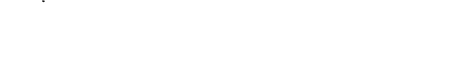 } & \multicolumn{10}{|c|}{ Case No } \\
\hline & 1 & 2 & 3 & 4 & 5 & 6 & 7 & 8 & 9 & Total No \\
\hline Important events in the child's life & - & + & - & - & - & + & + & + & + & 5 \\
\hline Presence of a model for their symptoms & - & - & - & - & + & + & + & + & - & 4 \\
\hline Past history of similar symptoms & - & + & + & + & - & + & - & + & - & 5 \\
\hline Concealed history & + & + & + & + & - & - & - & - & + & 5 \\
\hline Covert family problems & - & + & + & + & - & + & - & + & + & 6 \\
\hline Discrepant signs and function & + & + & + & + & + & + & + & + & + & 9 \\
\hline Signs did not localise lesion & + & + & + & + & + & + & + & + & + & 9 \\
\hline Total (maximum 8) & 4 & 7 & 6 & 6 & 4 & 7 & 5 & 7 & 6 & \\
\hline
\end{tabular}

$-=$ No, $+=$ Yes. 
and feet was apparent on $x$ ray pictures, with possible cortical bony loss in some areas. In view of this, despite the suspicion of functional disease, bone marrow was aspirated, examination of which was normal.

Her symptoms were thought to be largely psychological with some secondary sympathetic dystrophy. During assessment in hospital she said that her mother's boy friend was violent, and she had seen her mother being attacked and threatened on many occasions.

She was treated with psychotherapy and physiotherapy in hospital, and limped when her mother visited. The mother refused psychological and social help, and removed her daughter after six weeks. The girl hobbled out of the ward where the night before she had danced at a leaving party held for her by the nursing staff.

Table 1 shows the features in the nine children, and table 2 shows the diagnostic features in each case according to the criteria of Goodyer and Taylor. ${ }^{1}$

\section{Discussion}

Failure to walk usually implies severe organic disease and may therefore warrant complex and potentially harmful investigations. Although none of these nine children came to actual harm, cases 1 , 4,5 , and 6 were admitted for a number of investigations, case 2 nearly had an operation, and cases $3,5,6$, and 8 had invasive procedures performed before functional causes were seriously considered. In retrospect most of the tests were unnecessary, although at the time it was thought important to exclude organic disease. Indeed, in case 9 examination of the bone marrow was performed after the diagnosis of functional illness had been considered because an $x$ ray picture had suggested infiltration of the marrow.

Up to $30 \%$ of adults thought to have functional illness subsequently turn out to have organic disease ${ }^{2}$ and although this is not the case in this series it must be borne in mind. It is not until organic disease has been ruled out that most families are ready to consider the possibility of functional disease; premature discussion about this can antagonise parents. On the other hand, multiple tests to exclude the many possible diagnoses tend to reinforce parental belief that there is an organic basis for the symptoms.

Children with pains in the joints and limbs often have additional psychological problems. In a study of rhematological outpatients, $9 \%$ were thought to have functional illnesses that entirely accounted for their symptoms. ${ }^{3}$ Children who present with inability to walk may, however, be referred to other clinics. The cases reported here presented to rheumatological, orthopaedic, and neurological clinics; all doctors who treat children thus need to be aware of this presentation of functional illness.

It is important to look positively for functional illness to avoid potentially damaging investigations or treatment. The examination of the patient is the most useful pointer towards diagnosis. All our cases fulfilled the examination criteria cited by Goodyer and Taylor. All fulfilled at least four of the total of eight criteria, though fewer historical criteria were met.

Management is often difficult. Three points were made by Dubowitz and Hersov who reported five children with functional disorders of motor function. ${ }^{4}$ Firstly, investigations should be kept to a minimum, and must be stopped when the diagnosis is suspected. Secondly, they suggested that paramedical staff have an important part to play in management. This was so in our series. Experienced nursing staff observed discrepancies in the child's abilities in the ward in cases $1,3,8$, and 9 . Physiotherapists detected inconsistencies in the patient's claimed power deficits in cases $3,6,7$, and 8. After assessment a planned programme of physical activities should be started by an experienced physiotherapist in liaison with the clinician. This allows the child to regain full function while saving face and dignity.

Thirdly, psychiatric assessment should be requested to confirm the diagnosis, and find out why the child is behaving in such a way. Supportive psychotherapy for the child and the family during the period of follow up may assist rehabilitation. Six of our nine cases were seen by psychiatrists who uncovered more diagnostic information, and confirmed the diagnosis of functional illness in all. ${ }^{5}$ Not all families, however, agree to psychiatric consultation and follow up.

Identification of the unconscious need that is causing the symptoms is not always possible. Only two of our children had strong dislike of school as part of the reason for illness. Others were able to control their families at times when they felt in particular need of security. In most, several factors were undoubtedly present. Perhaps these children were all telling their families that they 'could not stand on their own two feet'.

There is a temptation to confront the child with suspicions about the functional nature of the diagnosis in an effort to terminate the episode. This should be resisted; it usually does not produce the desired effect, and there is a risk of precipitating deterioration in the presenting symptoms and, rarely, the appearance of new ones. 
The outcome in these cases ranges from rapid and total recovery to continuing disability. Those with persisting symptoms often defaulted from follow up or attended other clinics where the problem was managed as organic, so conferring respectability on the illness in the eyes of the parents and the child.

In the present series mother and child sometimes colluded in concealing crucial details, or frustrated attempts at treatment. In the latter circumstance it is important that the way is left open for the reestablishment of a treatment programme in the future, and to this end all effort should be made to maintain contact with the child and the family.

There were four children in whom the eventual outcome was poor; three had a score of seven and the fourth a score of six. It is possible that a high score at presentation would correlate with a poor outcome, but there are not enough children in this series to allow firm conclusions. It should be noted that the nature of some of the items in the score-for example, a concealed history-makes their identification at presentation difficult and the score incomplete.

Ideally, medical follow up of patients needs to be considerably longer than that for most of these cases, even if physical recovery appears complete. Psychosocial pressures may precipitate further symptoms related to stress that could be swiftly identified and treated, so avoiding morbidity. Five of these nine cases had had previous similar symptoms.

In conclusion, the appreciation of the functional nature of an illness in children presenting with disorders of gait may be aided if the eight criteria summarised here are used in the assessment of the child, those concerning the examination of the child being the most important.

We thank Dr JR Roberts for permission to report case 3.

\section{References}

${ }^{1}$ Goodyer I, Taylor DC. Hysteria. Arch Dis Child 1985;60:680-1.

2 Lloyd GG. Hysteria: a case for conservation? $\mathrm{Br}$ Med $\mathrm{J}$ 1986;293:1255-6.

3 Jacobs JC. Pediatric rheumatology for the practitioner. New York: Springer Verlag, 1982:162-4.

${ }^{4}$ Dubowitz V, Hersov L. Management of children with nonorganic (hysterical) disorders of motor function. Dev Med Child Neurol 1976;18:358-68.

${ }^{5}$ Mayou R. Sick role, illness behaviour and coping. $\mathrm{Br} J$ Psychiatry 1984;144:320-2.

Correspondence to $\mathrm{Dr}$ Alistair Thomson, Child Development Centre, Royal Liverpool Children's Hospital (Alder Hey), Liverpool L12 6AP.

Received 11 September 1987 